\title{
Influence of carbon fibre-reinforced polymers reinforcing on the seismic behaviour of timber-framed walls with fibre-plaster sheathing boards
}

\author{
M. Premrov \& P. Dobrila \\ Faculty of Civil Engineering, University of Maribor, Slovenia
}

\begin{abstract}
This paper provides an experimental analysis of timber-framed walls, coated with carbon fibre-reinforced polymers (CFRP) strengthened fibre-plaster boards. The presented wall elements are usually used as main bearing capacity elements in the construction of prefabricated multi-level timber residential buildings. Since the tensile strength of fibre-plaster sheathing boards (FPB) is approximately 10 times lower than the compressive strength, cracks in the tensile diagonal board's direction usually appear in tall buildings in heavy seismic areas. Therefore, in such cases, it is convenient to strengthen boards with high-strength materials in order to gain a higher capacity. It has been experimentally shown that the inclusion of CFRP diagonal strip reinforcement on the load-carrying capacity can be quite high and that it is maximized when the carbon strips are connected to the timber frame. On the other hand, the ductility itself was not significantly improved. Finally, a numerical study for FPB, which are glued to the timber frame and strengthened with CFRP strips, is preliminary presented for possible new technological solutions for treated wall elements in heavy seismic areas in the future.
\end{abstract}

Keywords: timber structures, walls, fibre-plaster boards, carbon fibres.

\section{Introduction}

There is an increasing tendency worldwide towards building multi-level prefabricated timber structures. It is clear to competitive fields of building that today's timber frame building is extremely highly valued and it is capable of 
fulfilling all demands from the society and environment that we live in. There are many arguments for timber-framed residential buildings, the most important being: very good building physical properties, built-in materials show environmental excellence, lower energy consumption, the speed of build and good seismic security.

The main bearing capacity vertical elements in timber-framed buildings are prefabricated timber-framed walls. The wall is a composite element consisting of framed panels made from sheets of board material fixed by mechanical fasteners to one or both sides of the timber frame (Figure 1). There are many types of panel products available that may have some structural capacity, such as woodbased materials (plywood, oriented strand board, hardboard, particleboard, etc.) or plaster boards and, more recently fibre-plaster boards. In the following analysis we limited our attention to the fibre-plaster boards (FPB), recently the most frequently used in Central Europe. One of the most important reasons for an increased application of these types of gypsum products is their relatively good fire protection. Additionally, gypsum is a healthy natural material and is consequently particularly desired for residential buildings.

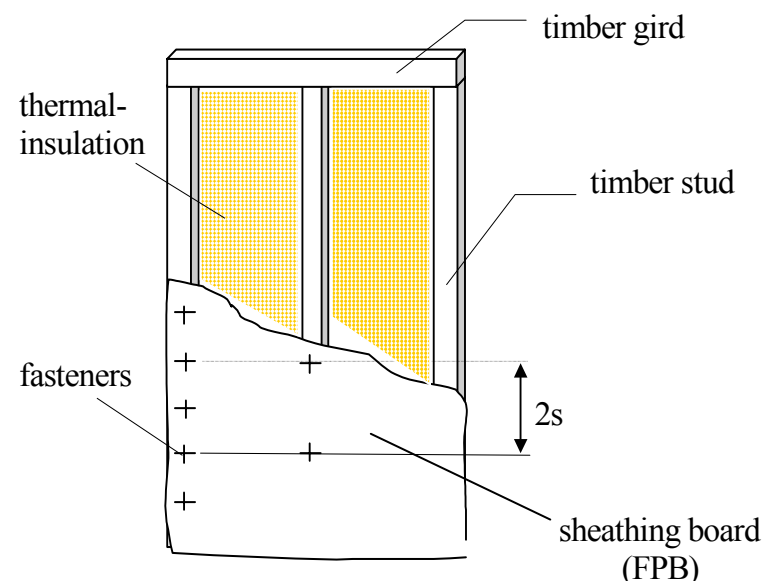

Figure 1: Composition of the timber-framed wall element.

From a structural point of view the tensile strength of FPB is very low, approximately 10 times lower than the compressive strength, and cannot be compared with the overall strength of the timber frame at all. Thus, especially in multi-level buildings located in seismic or windy areas, cracks in FPB usually appear. In these cases the FPB lose their stiffness and therefore the wall's horizontal stiffness rapidly decreases. Stresses in the timber frame under horizontal loads are usually not critical.

In structural analysis, panel walls for design purposes can be regarded separately as vertical cantilever beams with the horizontal force $\left(F_{H}=F_{H, t o t} / n\right)$ acting at the top (Figure 2). Considered supports approximate an influence on neighbouring panel walls and assure an elastic-clamped boundary condition for the treated wall (EN 1995-1-1:2005 [1] or Faherty and Williamson [2]). 


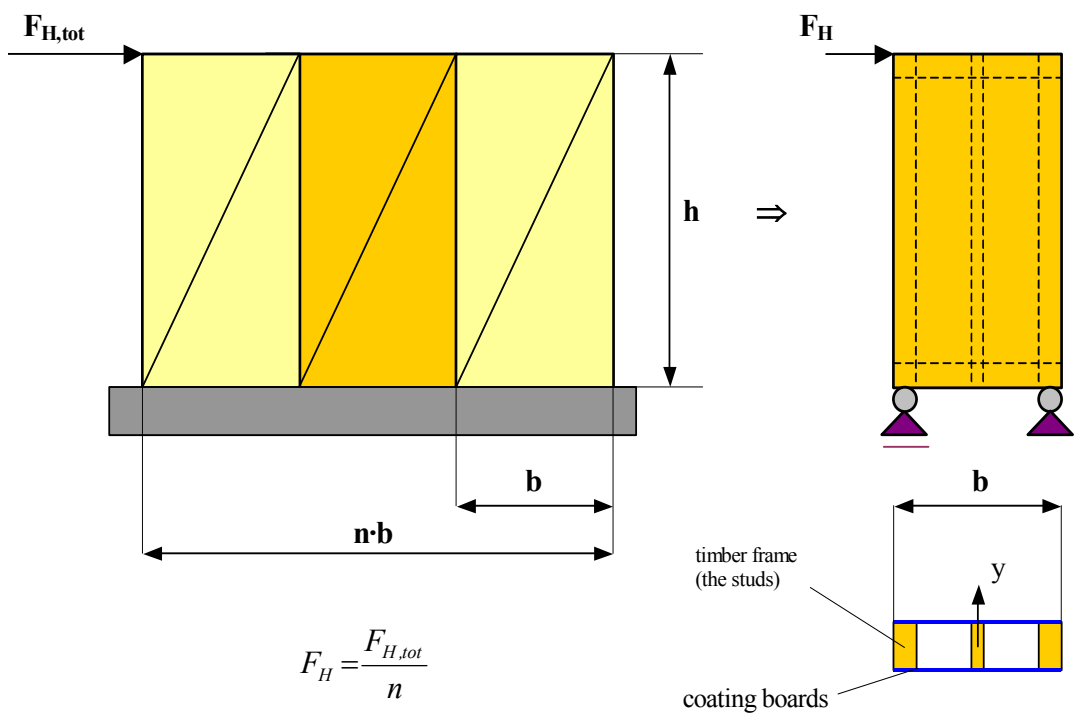

Figure 2: $\quad$ Static design and cross section of the treated wall element.

\section{Mathematical modelling of the walls}

Many design models have been proposed in order to analyse and predict the behaviour of wall diaphragms subjected to lateral loads.

\subsection{Simplified shear model (Eurocode 5 methods)}

Källsner [3] and Äkerlund [4] proposed an agreeable approach to determine the load-carrying capacity of the wall unit, based on the following key assumptions:

- behaviour of the joints between the sheet and the frame members is assumed to be linear-elastic until failure,

- the frame members and the sheets are assumed to be rigid and hinged to each other.

Two simplified computational methods are given in EN 1995-1-1 [1] in order to determine the load-carrying capacity of the wall diaphragm. The first Method A - is identical to the 'Lower bound plastic method', presented by Källsner and Lam [5]. This method defines the characteristic wall's shear resistance $\left(F_{v, R k}\right)$ as a sum of all the characteristic fasteners' shear resistances $\left(F_{f, R k}\right)$ :

$$
F_{v, R k}=\sum F_{f, R k} \cdot \frac{b}{s} \cdot c
$$




$$
c=\left\{\begin{array}{ll}
1 & \text { for } b \geq b_{0} \\
\frac{b}{b_{0}} & \text { for } b \leq b_{0}
\end{array} \quad \text { where } b_{0}=h / 2\right.
$$

This method is usually unsuitable for treated walls sheathed with fibre-plaster boards (FPB). The main assumptions do not exactly coincide with the real state of FPB, in which the tensile strength is evidently lower than the compressive strength. Consequently, cracks in a tensile zone in FPB usually appear under heavy horizontal loads before stresses on the fasteners reach their yielding point, and the fibreboards do not usually behave as rigid elements (Dobrila and Premrov [6]). Consequently, there is no need to reinforce the coating boards and therefore there are no special expressions to consider the influence of steel or carbon fibre-reinforced polymers (CFRP) diagonal reinforcement.

\subsection{Composite model}

Described walls, consisting of a timber frame and fibre-plaster boards (FPB), should be treated as composite elements. By employing FPB as a coating material, a horizontal load shifts a part of the horizontal force over the mechanical fasteners to the fibreboard and the wall acts like a deep beam. Following the semi-analytical procedure, described in detail in Premrov and Dobrila [7], we developed a mathematical model that enables simultaneous consideration of:

- flexibility of mechanical fasteners between the boards and the timber frame;

- formation of cracks in a tensile area of fibre-plaster boards;

- influence of CFRP strips that are glued to the FPB and to the timber frame.

The proposed semi-analytical mathematical model is based on the classical beam theory, taking into account a fasteners' flexibility in the timber frame - FPB connecting to the area by using the s.c. " $\gamma$-procedure". Therefore, the CFRP strip contribution is considered with a modified slip modulus, which results in the fictive increased stiffness coefficient of the fasteners $\left(\gamma_{y i}{ }^{*}\right)$. With regard to the fictive designing enlarged cross-section of FPB, the approximate analytical model with fictitiously enlarged thickness $\left(t^{*}\right)$ of the FPB is proposed in the form of:

$$
t^{*}=\frac{A_{l b}^{*}}{b}=t+\frac{1}{\chi} \cdot \frac{E_{s}}{G_{b}} \cdot \sin ^{2} \alpha \cdot \cos \alpha \cdot A_{1 s, 0} \cdot \frac{1}{b}
$$

In the above equations $\alpha$ represents the angle of the inserted CFRP diagonals with the net area $\left(A_{l s, 0}\right)$. A non-dimensional coefficient $\chi$ is a shear cross-section coefficient defined as a proportion between the shear and actual cross-sectional area of the FPB with the shear modulus $\left(G_{b}\right)$. The whole procedure is developed as in all steps in [7] and will not be presented in this paper. However, it is important to note that in the case of a cantilever with a linear moment distribution (such as the walls being considered), the $\gamma$-model is an approximation only. It may be interesting to analyze the structural behaviour with a more accurate model (for example a FE model) and compare the numerical results with the proposed mathematical model, which is made at the end of this paper. 


\section{CFRP strengthening of the walls}

\subsection{Methods of strengthening}

In order to avoid any cracks appearing in the tensile area of the FPB there are several possibilities to strengthen the walls:

- by using additional boards;

- by reinforcing boards with steel diagonals;

- by reinforcing boards with carbon or high-strength synthetic fibres.

In [6] we presented the first possibility experimentally using additional FPB, which gave higher elasticity of elements, whilst bearing capacity and, in particular, ductility, were not improved in the desired range.

With the intention to improve the resistance and especially the ductility of the walls it is more convenient to insert diagonal steel strips, which have to be fixed to the timber frame. In this case only a part of the horizontal force is shifted from boards over the tensile steel diagonal to the timber frame after the appearance of the first crack in the tensile zone of the FPB (see [6]). From the measured forces forming the first crack it is evident that the inserted steel diagonals are not very important. However, the proportion between the measured destruction forces shows that the resistance of the reinforced panels increases by $77 \%$ [6]. It is also important that ductility is strongly improved.

As the tensile strength of the FPB is obviously lower than the compressive strength and the corresponding capacity of the timber frame, the treated elements tend to fail because the cracks are forming in the tensile area of the FPB, therefore this tensile area could be reinforced with high-strength materials. This strengthening concept is such that the composites would contribute to the tensile capacity of boards when the tensile strength of the FPB is exceeded.

\subsection{Strengthening with CFRP strips - experimental analysis}

\subsubsection{Test configuration}

Three sample groups from a total of nine test samples were tested in order to carry out appropriate experimental research on the influence of CFRP strengthened walls. All test groups consisted of three walls of actual dimensions $h=263.5 \mathrm{~cm}$ and $b=125 \mathrm{~cm}$. The cross-section presented in Figure 1 was composed of timber studs $(2 \times 9 \times 9 \mathrm{~cm}$ and $1 \times 4.4 \times 9 \mathrm{~cm})$, timber girders $(2 \times 8 \times 9 \mathrm{~cm})$ and Knauf fibre-plaster boards (Knauf [8]) of thickness $t=15 \mathrm{~mm}$. They were fixed to the timber frame using staples of $\Phi 1.53 \mathrm{~mm}$ at an average spacing of $s=75 \mathrm{~mm}$.

The static model shown in Figure 2 was used for all groups of test samples. The samples were actually rotated by $90^{\circ}$ as shown in Figure 2 and they were therefore subjected to vertical force acting at the end of the elements (Figure 4(a)). The FPB were reinforced in the tensile diagonal area using SikaWrap230C strips (Sika [10]) made from carbon high-strength fibre reinforced polymers of thickness $1.2 \mathrm{~mm}$. Strips with different widths $(300$ or $600 \mathrm{~mm}$ ) and of different boundary conditions were glued to the FPB. 
The first group (G1) of three test samples was additionally reinforced with two CFRP diagonal strips (one in each FPB) of width $300 \mathrm{~mm}$, which were glued on the FPB using Sikadur-330 LVP. The strips were additionally glued to the timber frame (Figure 4(a)) to ensure the transmission of the force from the FPB to the timber frame.

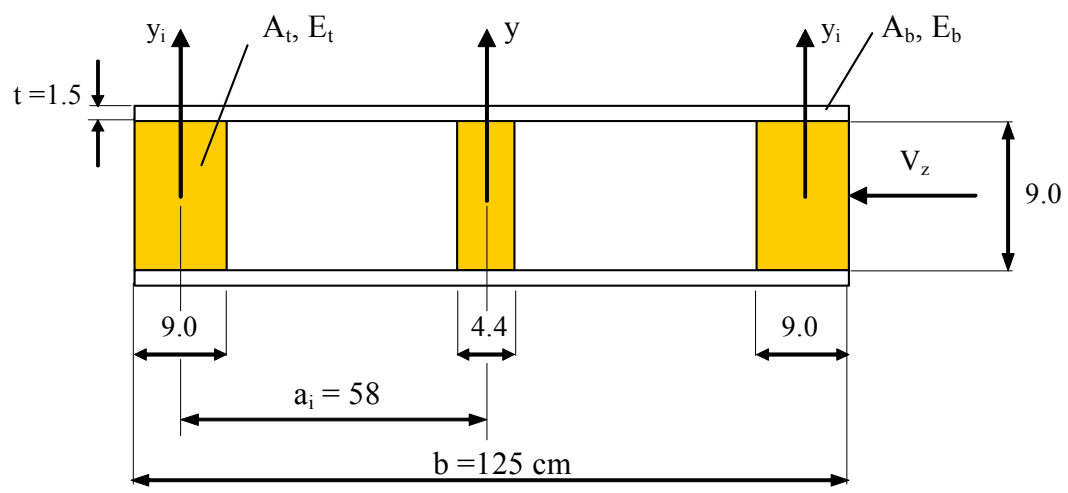

Figure 3: $\quad$ Cross-section of test samples.

The second group (G2) of three test samples was additionally reinforced with two CFRP diagonal strips of width $600 \mathrm{~mm}$. The strips were glued on the FPB and to the timber frame as in G1 (Figure 4(a)) to ensure the transmission of the force from the FPB to the timber frame.

(a)

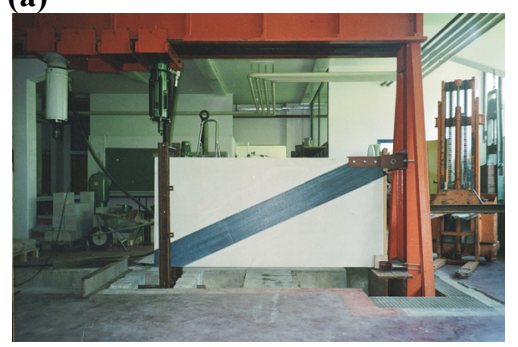

(b)

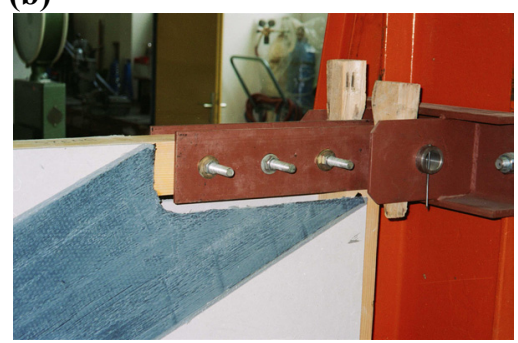

Figure 4: (a) Static design used by the test samples. (b) Boundary condition for $\mathrm{G} 3$.

Table 1: $\quad$ Properties of the used materials.

\begin{tabular}{|l|c|c|c|c|c|c|}
\hline & $\begin{array}{c}\mathrm{E}_{0, \mathrm{~m}} \\
\left(\mathrm{~N} / \mathrm{mm}^{2}\right)\end{array}$ & $\begin{array}{c}\mathrm{G}_{\mathrm{m}} \\
\left(\mathrm{N} / \mathrm{mm}^{2}\right)\end{array}$ & $\begin{array}{c}\mathrm{f}_{\mathrm{m}, \mathrm{k}} \\
\left(\mathrm{N} / \mathrm{mm}^{2}\right)\end{array}$ & $\begin{array}{c}\mathrm{f}_{\mathrm{t}, 0, \mathrm{k}} \\
\left(\mathrm{N} / \mathrm{mm}^{2}\right)\end{array}$ & $\begin{array}{c}\mathrm{f}_{\mathrm{c}, 0, \mathrm{k}} \\
\left(\mathrm{N} / \mathrm{mm}^{2}\right)\end{array}$ & $\begin{array}{c}\rho_{\mathrm{m}} \\
\left(\mathrm{kg} / \mathrm{m}^{3}\right)\end{array}$ \\
\hline Timber & 10000 & 630 & 22 & 13 & 20 & 410 \\
\hline FPB & 3000 & 1200 & 4.0 & 2.5 & 20 & 1050 \\
\hline Sika & 231000 & $/$ & $/$ & 4100 & $/$ & 1920 \\
\hline
\end{tabular}


The third group (G3) of three test samples was additionally reinforced with two CFRP diagonal strips of width $300 \mathrm{~mm}$ as in G1, but they were not glued to the timber frame (Figure 4(b)).

Material properties for the test samples for all groups were the same (Table 1). Values for timber of quality $\mathrm{C} 22$ are taken from EN338 [9], the characteristics of fibre-plaster boards from Knauf [8] and for carbon strips Sika [10] was used.

\subsubsection{Test results and analysis}

The force forming the first crack $\left(F_{c r}\right)$ in the FPB, the crushing force $\left(F_{u}\right)$ and the maximal cantilever bending deflection $(w)$ under the acting force $(F)$ were all measured. The measured values for the un-strengthened (UNS) test samples were taken from [4] and included for information and comparison only. The calculated numerical values for G1 and G2 are taken from [7] to confirm the applicability of the presented semi-analytical mathematical model, which is necessary for applicability of the numerical analysis presented in Section 4.

Average force forming the first crack $\left(\mathrm{F}_{\mathrm{cr}}\right)$ :

$$
\text { G1: } F_{c r, 1}=24.28 \mathrm{kN} \quad \mathrm{G} 2: \quad \mathrm{F}_{\mathrm{cr}, 2}=32.13 \mathrm{kN}
$$

G3: $F_{\text {cr,3 }}=35.90 \mathrm{kN} \quad$ UNS: $F_{\text {cr,uns }}=17.67 \mathrm{kN}$

Mathematical model [7]:

$$
\mathrm{G} 1: \mathrm{F}_{\mathrm{cr}, 1}=\quad 23.39 \mathrm{kN} \quad \mathrm{G} 2: \quad \mathrm{F}_{\mathrm{cr}, 2}=31.75 \mathrm{kN}
$$

Average crushing force $\left(\mathrm{F}_{\mathrm{u}}\right)$ :

$$
\begin{array}{ll}
\mathrm{G} 1: \mathrm{F}_{\mathrm{u}, 1}=40.33 \mathrm{kN} \quad \mathrm{G} 2: & \mathrm{F}_{\mathrm{u}, 2}=46.27 \mathrm{kN} \\
\text { G3: } \mathrm{F}_{\mathrm{u}, 3}=\quad 36.26 \mathrm{kN} & \mathrm{UNS}: \mathrm{F}_{\mathrm{u}, \mathrm{uns}}=26.02 \mathrm{kN} \\
\text { Mathematical model [7]: } & \\
\text { G1: } \mathrm{F}_{\mathrm{u}, 1}=42.68 \mathrm{kN} \quad \mathrm{G} 2: & \mathrm{F}_{\mathrm{u}, 2}=43.70 \mathrm{kN}
\end{array}
$$

It is evident that a coincidence between the measured and numerical results is very good, so it is good "support" for numerical analysis in Section 4.

Following the measured results only, we can conclude that the force forming the first crack essentially increased for all kinds of CFRP strengthened test samples, but mostly for samples G3, where the CFRP strips were not fixed to the timber frame. When comparing the measured results of the crushing force, a greater improvement can be noticed in the groups where the CFRP diagonals were glued to the timber frame. Compared to the un-strengthened test sample, the crushing force in samples G2 was increased by $78 \%$. In samples G3 the crushing force practically coincided with a force forming the first crack, so cracks hardly appeared at all, which is not a good solution to ensure better ductility, necessary for seismic design.

For further analysis it is important to present measured maximal cantilever deflections $(w)$ under the force $F_{H}$. They are presented in Figure 5.

From Figure 5 we can make the following important conclusions:

- There was no essential influence on the element stiffness of any reinforcement before cracks appeared in tensile area of un-strengthened FPB.

- The elastic resistance (force forming the first crack) essentially increased for all kinds of CFRP strengthened test samples.

- It has been shown that the inclusion of CFRP diagonal strip reinforcement on the load-carrying capacity can be quite high and that it is maximized when the carbon strips were additionally glued to the timber frame. 


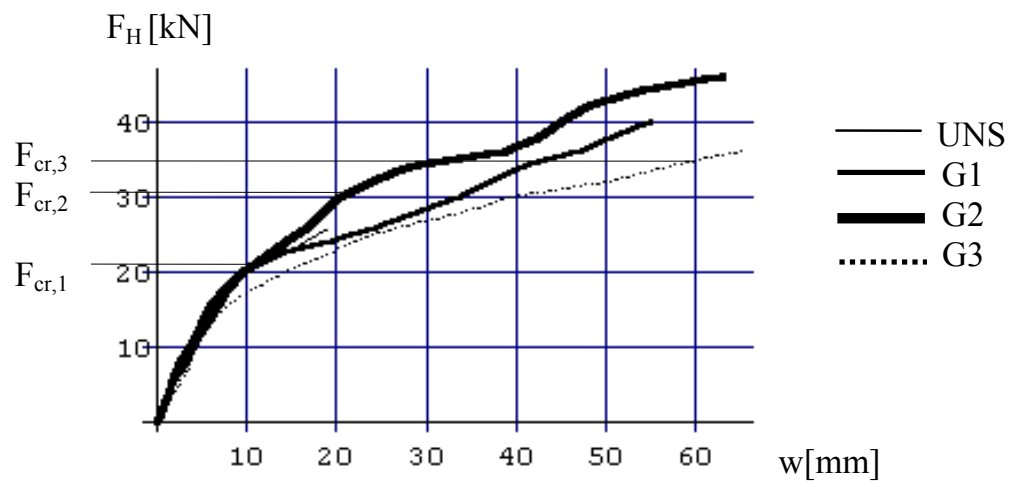

Figure 5: $\quad$ Measured average bending deflections (w).

\section{FEM analysis - FPB are glued to the timber frame}

As it was mentioned in Section 2.2, a semi-analytical mathematical model was developed [7], which enables a simultaneous consideration of fasteners flexibility, formation of cracks in a tensile area of FPB and the influence of inserted CFRP diagonals. Since the wall element is treated as a composite system, the wall's behaviour strongly depends on the fasteners disposition, which is already experimentally tested on wall elements with doubled FPB on each side [11]. Therefore, it is interesting to analyse a fully new possible technological solution when the FPB are not mechanically connected to the timber frame, but they are glued to the timber studs and girders. Since there are no experimental results at this time available, we will preliminary analyse the wall elements using the presented mathematical composite model from [7], as well as a commercial software package Tower 6 for nonlinear structural analysis.

We will analyse the same test sample as in Section 3 - the G1 test group, with an important distinction that $\gamma_{y i}=1.0$. The test sample will be numerical analysed with two different calculation methods:

a) a composite semi-analytical mathematical model with $t^{*}=2.541 \mathrm{~cm}$ (Eq. 4),

b) FE nonlinear structural analysis using commercial programme package

Tower 6 using a finite element mesh with 1846 nodes (Figure 6(a)). Stress

distribution in FPB by force $F_{H}=40 \mathrm{kN}$ are presented in Figure 6(b).

The calculated results obtained by the both mathematical models are presented in Table 2.

It is evident from the presented results that in the case when the FPB are glued to the timber frame force forming the first crack in the FPB essentially increases (for $78 \%$ comparing with the test group G1). It is logical because the stress distribution in the whole wall element strongly depends on the shear stiffness in the connection plane between the boards and the timber frame. Since in case when $\gamma_{y}=1.0$ a bigger part of the horizontal force is shifted to the timber frame, normal stresses in the timber frame increase and in the FPB decrease. Therefore, cracks in the FPB appear almost by the same force as the tensile cracks in the timber frame. 
(a)

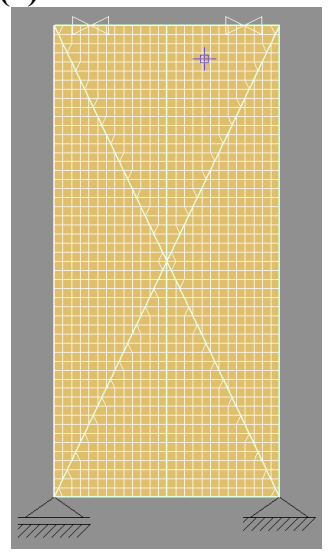

(b)

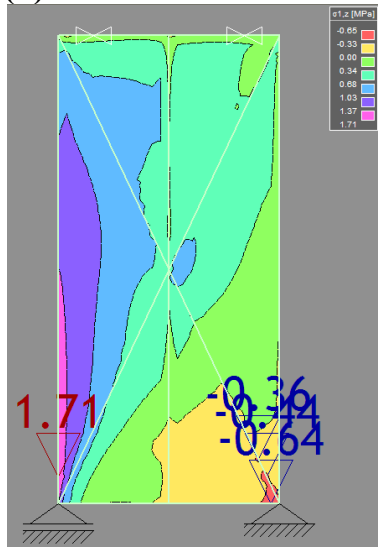

Figure 6: (a) FE mesh generation. (b) Stresses in the FPB.

Table 2: Calculated results using the semi-analytical composite and the Tower 6 model.

\begin{tabular}{|c|c|c|c|c|c|c|}
\hline $\mathrm{F}[\mathrm{kN}]$ & Math. model & $\begin{array}{c}\mathrm{w} \\
(\mathrm{mm})\end{array}$ & $\begin{array}{c}\sigma_{\mathrm{FRP}, \mathrm{t}} \\
(\mathrm{MPa})\end{array}$ & $\begin{array}{c}\sigma_{\mathrm{FRP}, \mathrm{c}} \\
(\mathrm{MPa})\end{array}$ & $\begin{array}{c}\sigma_{\text {timb,t }} \\
(\mathrm{MPa})\end{array}$ & $\begin{array}{c}\sigma_{\text {timb,c }} \\
(\mathrm{MPa})\end{array}$ \\
\hline \multirow{2}{*}{10} & Composite m. & 1.035 & 0.601 & 0.601 & 2.003 & 2.003 \\
& Tower 6 m. & 0.883 & 0.430 & 0.160 & 1.609 & 1.457 \\
\hline \multirow{2}{*}{40} & Composite m. & 4.141 & 2.403 & 2.403 & 8.010 & 8.010 \\
& Tower 6 m. & 3.532 & 1.710 & 0.640 & 6.457 & 5.830 \\
\hline 41.614 & Composite m. & 4.308 & $/$ & 2.500 & 12.317 & 8.333 \\
$=\mathrm{F}_{\text {cr.c.m. }}$ & Tower 6 m. & 3.675 & 1.779 & 0.666 & 6.718 & 6.065 \\
\hline 43.923 & Composite m. & 4.500 & $/$ & 2.644 & 13.000 & 8.812 \\
$=\mathrm{F}_{\text {u.c.m. }}$ & Tower 6 m. & 3.878 & 1.878 & 0.703 & 7.092 & 6.402 \\
\hline
\end{tabular}

\section{Conclusions}

From the presented experimental and numerical analysis we can make some basic conclusions in two main parts.

When fibre-plaster boards (FPB) are mechanically connected to the timber frame the boards are "a weaker part" of the structure and they are usually subjected to the cracks appearing. Therefore, in order to avoid cracks, strengthening with CFRP strips, placed in a tensile diagonal direction of FPB, is recommended when timber-frame buildings are subjected to heavy horizontal forces. The costs of employing CFRP are at the moment rather high, but experimental results presented here justified these high costs with much higher forces forming the first crack, load-carrying capacity and stiffness increase. 
Distribution of the normal stresses in the whole wall element strongly depends on the shear stiffness in the connection plane between the boards and the timber frame. To avoid cracks appearing in FPB is therefore a good prediction to glue the boards to the timber frame. In this case a bigger part of the horizontal force is shifted to the timber frame and consequently, cracks in FPB appear just a little before the timber frame failure in tension. To confirm the presented facts obtained from Section 4 it would be necessary experimentally to test the walls.

\section{References}

[1] CEN/TC 250/SC5 N173, EN 1995-1-1:2005, Eurocode 5: Design of Timber Structures, Part 1-1 General rules and rules for buildings: Brussels, 2005.

[2] Faherty, K.F, Williamson, T.G., Wood Engineering and Construction Handbook, McGraw-Hill Publishing Company, 1989.

[3] Källsner, B., Panels as wind-bracing elements in timber-framed walls, Swedish Institute for Wood Technology Research, Rep. 56, Stockholm, 1984.

[4] Äkerlund, S., Simple calculation model for sheets on a timber frame, Bygg \& Teknik, No.1, 1984.

[5] Källsner, B., Lam, F., Diaphragms and shear walls. Holzbauwerke: Grundlagen, Entwicklungen, Ergänzungen nach Eurocode 5, Step 3, Fachverlag Holz: Düsseldorf, pp. 15/1-17, 1995.

[6] Dobrila, P., Premrov, M., Reinforcing methods for composite timber framefiberboard wall panels, Engineering Structures 25(11), pp. 1369-1376, 2003.

[7] Premrov, M., Dobrila, P., Modelling of Fastener Flexibility in CFRP Strengthened Timber-Framed Walls Using Modified $\gamma$ - Method, Engineering Structures 30 (1), pp. 368-375, 2007.

[8] Knauf Gipsfaserplatten Vidivall/Vidifloor, 2002.

[9] European Committee for Standardization, EN 338:2003 E: Structural timber - Strength classes: Brussels, 2003.

[10] Sika, Sicher bauen mit System. Technische Merkblätter. Ausgabe 5; 2003.

[11] Kuhta, M., Premrov, M., Influence of Fasteners Disposition on Behaviour of Timber-Framed Walls with Double Fibre-Plaster Coating Boards, American Journal of Applied Sciences 5 (1), pp. 1-6, 2007. 